\title{
Appetite Loss as an Adverse Effect During Treatment with EGFR-TKIs in Elderly Patients with Non-small Cell Lung Cancer
}

\author{
MINEHIKO INOMATA ${ }^{1}$, KAZUKI SHIMOKAWA $^{2}$, KOTARO TOKUI $^{2}$, CHIHIRO TAKA $^{2}$, \\ SEISUKE OKAZAWA ${ }^{2}$, KENTA KAMBARA ${ }^{2}$, TORU YAMADA ${ }^{2}$, TOSHIRO MIWA ${ }^{2}$, \\ RYUJI HAYASHI ${ }^{2}$, TATSUHIKO KASHII ${ }^{3}$, SHOKO MATSUI ${ }^{4}$ and KAZUYUKI TOBE ${ }^{2}$ \\ ${ }^{1}$ Center for Clinical Research and ${ }^{3}$ Department of Medical Oncology, \\ Toyama University Hospital, Toyama, Japan; \\ ${ }^{2}$ First Department of Internal Medicine, ${ }^{4}$ Center for Health Care and Human Sciences, \\ University of Toyama, Toyama, Japan
}

\begin{abstract}
Aim: We conducted a retrospective study to investigate the frequency of appetite loss during treatment with epidermal growth factor receptor tyrosine kinase inhibitor (EGFR-TKI) in elderly patients, aged 75 years or older, with non-small cell lung cancer harboring EGFR gene mutations. Patients and Methods: Data of a total of 64 patients, including 39 relatively young (hereinafter, younger) patients and 25 elderly patients were analyzed. Results: Appetite loss of all grades $(p=0.074)$ and of grade 3 or greater $(p=0.030)$ was more frequently observed in elderly patients. Diarrhea and oral mucositis were also more frequent in elderly patients, although they did not reach statistical significance. No apparent differences were observed in the frequency of aspartate aminotransferasel alanine aminotransferase elevation, skin rash or fatigue between the two patient groups. The median (95\% confidence interval) progression-free survival times were 10.8 (6.6-16.4) months and 11.8 (4.420.3) months in the younger and elderly patient groups, respectively. Conclusion: Our findings suggest that appetite loss is a major adverse effect in elderly patients with non-small cell lung cancer receiving treatment with EGFR-TKIs.
\end{abstract}

Correspondence to: Minehiko Inomata MD, Ph.D., Center for Clinical Research, Toyama University Hospital, Sugitani 2630, Toyama City 930-0194, Japan. Tel: +81 76434 7287, Fax: +81 764345025,e-mail: minomata@med.u-toyama.ac.jp

Key Words: Epidermal growth factor receptor, lung cancer, elderly, adverse effects.
In patients with metastatic lung cancer, systemic treatment is the standard therapeutic choice. While it is difficult to expect cure with systemic drug therapy in patients with metastatic lung cancer, platinum-based doublet chemotherapy has been demonstrated to offer survival benefit (1), and recently, maintenance chemotherapy $(2,3)$ and targeted therapy (4-7) have yielded further prolongation of patient survival.

Among these, epidermal growth factor receptor tyrosine kinase inhibitors (EGFR-TKIs) have been demonstrated to confer an impressive prolongation of survival in patients with lung cancer harboring mutant epidermal growth factor receptor $(E G F R)$. Although most of these clinical studies of EGFR-TKI included patients who were aged 75 years or younger, several studies have shown that treatment with EGFR-TKIs, including gefitinib and erlotinib, offer survival benefit also in elderly patients with this type of cancer (8-13). These studies showed an acceptable incidence of adverse events in elderly lung cancer patients receiving treatment with EGFR-TKIs. Skin rash, hepatic injury, diarrhea and interstitial lung disease are well-known adverse effects of EGFR-TKIs, and it has been shown that these events did not increase in incidence in elderly patients with lung cancer harboring EGFR mutations receiving treatment with EGFR-TKIs.

However, appetite loss, occurring as one of the reported adverse events of treatment with EGFR-TKIs, may be a problem in the treatment of elderly patients. The frequency of appetite loss is not high in younger patients; the incidence was reported to be $14.9 \%$ in the NEJ 002 trial (4), while the incidence was not reported in the WJTOG 3405 trial (5), which included patients aged 75 years or younger. On the other hand, observational and intervention studies in elderly patients with lung cancer with EGFR gene mutations reported appetite loss in 29 to $50 \%$ of cases (10-13). 
Although two of the studies did not report any case of appetite loss $(8,9)$, this could be because of differences in the study design or method of data collection.

Because elderly patients have impaired organ function, cytotoxic drugs are often avoided because of the high incidence of adverse effects. EGFR-TKIs occupy an important position in the treatment of metastatic lung cancer, and an awareness of the adverse effects of EGFR-TKIs in elderly patients is essential. We conducted a retrospective study in order to investigate the frequency of appetite loss and other adverse events in elderly patients receiving treatment with EGFR-TKIs as compared to younger patients.

\section{Patients and Methods}

Data collection and endpoint. This retrospective study was conducted by reviewing the medical charts of patients of Toyama University Hospital, after obtaining the approval of the Ethical committee, University of Toyama (reference number: 28-21). The primary endpoint was the frequency of appetite loss, and the secondary endpoints were the frequencies of other adverse events and the progression-free survival. Information about the adverse events of appetite loss, aspartate aminotransferase/alanine aminotransferase (AST/ALT) elevation, diarrhea, skin rash, fatigue, interstitial lung disease and oral mucositis arising during the treatment period (from the day of initiation of EGFR-TKI treatment to the day of documentation of disease progression) was evaluated. The patient inclusion criteria were: patients with histologically or cytologically confirmed non-small lung cancer harboring EGFR gene mutations other than T790M, and patients treated with EGFRTKIs between 2004 and 2016. The exclusion criteria were: patients previously treated with EGFR-TKI, malignancy other than lung cancer, patients who could be observed for less than 1 month, and those with a psychiatric disorder.

Statistical analysis. JMP version 11. 2. 0 (SAS Institute, Cary, NC, USA) was used for the statistical analysis. Patients were divided into two groups according to their age: the younger group, consisting of patients who were 74 years of age or younger, and the elderly group, consisting of patients who were 75 years of age or older. The frequencies of the observed adverse events were compared between the elderly and younger patient groups by Fischer's exact test. Progression-free survival was calculated from the date of initiation of the EGFR-TKI treatment to the date of documentation of disease progression. Disease progression was determined based on the Response Evaluation Criteria in Solid Tumors, version 1.1 (14).

\section{Results}

Patient characteristics. Table I shows the patient characteristics. We reviewed the data of a total of 64 patients, including 39 patients comprising the younger patient group and 25 elderly patients. Slightly more elderly patients had a poorer performance status, more often received gefitinib than erlotinib, and received EGFR-TKI treatment as first-line therapy.
Table I. Patient characteristics.

\begin{tabular}{lcc}
\hline Age, years & $<75$ & $\geq 75$ \\
\hline Number & 39 & 25 \\
Gender, n (\%) & & \\
$\quad$ Male & $16(41.0 \%)$ & $12(48.0 \%)$ \\
$\quad$ Female & $23(59.0 \%)$ & $13(52.0 \%)$ \\
Histology, n (\%) & & \\
$\quad$ Adenocarcinoma & $38(97.4 \%)$ & $23(92.0 \%)$ \\
$\quad$ Squamous & $1(2.6 \%)$ & $1(4.0 \%)$ \\
$\quad$ Adenosquamous & $0(0.0 \%)$ & $1(4.0 \%)$ \\
EGFR status, n (\%) & $34(87.2 \%)$ & $23(92.0 \%)$ \\
$\quad$ Common mutation & $5(12.8 \%)$ & $2(8.0 \%)$ \\
$\quad$ Uncommon mutation & & \\
PS & $29(74.4 \%)$ & $16(64.0 \%)$ \\
$\quad 0-1$ & $10(25.6 \%)$ & $9(36.0 \%)$ \\
$\quad \geq 2$ & $27(69.2 \%)$ & $21(84.0 \%)$ \\
Prior treatment regimens, n $(\%)$ & $12(30.8 \%)$ & $4(16.0 \%)$ \\
$\quad 0$ & & \\
$\geq 1$ & $29(74.4 \%)$ & $21(84.0 \%)$ \\
EGFR-TKI, n (\%) & $10(25.6 \%)$ & $4(16.0 \%)$ \\
$\quad$ Gefitinib &
\end{tabular}

EGFR-TKI: Epidermal growth factor receptor tyrosine kinase inhibitor; PS: performance status. Common mutation includes exon 21 L858R and exon 19 deletion, and uncommon mutation includes other rare mutations.

Adverse events and survival. Table II shows the frequency of adverse events observed during the treatment with EGFRTKIs. Appetite loss of all grades was more frequently observed in the elderly patient group $(p=0.074)$. Appetite loss of grade 3 or greater was observed in one (2.6\%) patient of the younger patient group and five $(20.0 \%)$ patients of the elderly patient group $(p=0.030)$. Determination of grade 3 or more appetite loss was based on the need for hospital admission due to appetite loss, apparent body weight loss, or the decision of the physician in charge. Of these patients, one patient of the younger patient group developed brain infarction, and one patient of the elderly patient group showed concomitant disease progression. It is possible that appetite loss in these two patients was derived from their complication or disease progression, and not a result of EGFR-TKI treatment. However, even after excluding these two patients, grade 3 or more appetite loss was encountered significantly more frequently in the elderly patient group $(p=0.019)$. Diarrhea and oral mucositis were also more frequent in elderly patients, although the differences from the younger group in their incidence did not reach statistical significance. In contrast, there were no apparent differences in the frequencies of AST/ALT elevation, skin rash, fatigue, or interstitial lung disease between the younger and elderly patient groups. The proportion of patients that needed 
Table II. Adverse events experienced by patients receiving epidermal growth factor receptor tyrosine kinase inhibitor.

\begin{tabular}{|c|c|c|c|}
\hline Age, years & $<75$ & $\geq 75$ & $p$-Value \\
\hline \multicolumn{4}{|l|}{ Appetite loss } \\
\hline All grades & $14(35.9 \%)$ & $15(60.0 \%)$ & 0.074 \\
\hline Grade $\geq 3$ & $1(2.6 \%)$ & $5(20.0 \%)$ & 0.030 \\
\hline \multicolumn{4}{|l|}{ Oral mucositis } \\
\hline All grades & $6(15.4 \%)$ & $7(28.0 \%)$ & 0.340 \\
\hline Grade $\geq 3$ & $0(0.0 \%)$ & $2(8.0 \%)$ & 0.149 \\
\hline \multicolumn{4}{|l|}{ Diarrhea } \\
\hline All grades & $15(38.5 \%)$ & $13(52.0 \%)$ & 0.313 \\
\hline Grade $\geq 3$ & $0(0.0 \%)$ & $0(0.0 \%)$ & \\
\hline \multicolumn{4}{|l|}{ Skin rash } \\
\hline All grades & $27(69.2 \%)$ & $19(76.0 \%)$ & 0.776 \\
\hline Grade $\geq 3$ & $3(7.7 \%)$ & $4(16.0 \%)$ & 0.417 \\
\hline \multicolumn{4}{|l|}{ Paronychia } \\
\hline All grades & $17(43.6 \%)$ & $7(28.0 \%)$ & 0.291 \\
\hline Grade $\geq 3$ & $2(5.1 \%)$ & $1(4.0 \%)$ & 1.000 \\
\hline \multicolumn{4}{|l|}{ Malaise } \\
\hline All grades & $7(18.0 \%)$ & $3(12.0 \%)$ & 0.728 \\
\hline Grade $\geq 3$ & $0(0.0 \%)$ & $0(0.0 \%)$ & \\
\hline \multicolumn{4}{|l|}{ Pneumonitis } \\
\hline All grades & $0(0.0 \%)$ & $1(4.0 \%)$ & 0.391 \\
\hline Grade $\geq 3$ & $0(0.0 \%)$ & $1(4.0 \%)$ & 0.391 \\
\hline \multicolumn{4}{|l|}{ AST/ALT } \\
\hline All grades & $24(61.5 \%)$ & $17(68.0 \%)$ & 0.790 \\
\hline Grade $\geq 3$ & $4(10.3 \%)$ & $5(20.0 \%)$ & 0.296 \\
\hline
\end{tabular}

AST/ALT: Aspartate aminotransferase/alanine aminotransferase.

discontinuation or reduction in the dose of the EGFR-TKIs was not significantly different between the two patient groups (33\% in the younger patient group and $44 \%$ in the elderly patient group).

Figure 1 shows the Kaplan-Meier curve for progression-free survival in the younger and elderly patient groups. The median (95\% confidence interval) progression-free survival was 10.8 (6.6-16.4) months in the younger patient group and 11.8 (4.420.3) months in the elderly patient group; the difference in the progression-free survival duration between the two groups was not statistically significant $(p=0.862, \log$-rank test). However, within the elderly patient group, the progression-free survival time was significantly shorter (median: 2.5 months, 95\% confidence interval: 1 month - not estimated) in the patients with grade 3 or more appetite loss than in the patients without grade 3 or more appetite loss (median: 11.8 months, 95\% confidence interval: 5.8-21.9 months, $p=0.046$ ).

\section{Discussion}

The present study showed that appetite loss was more frequently observed in elderly patients during treatment with EGFR-TKIs, including gefitinib and erlotinib. In patients aged 74 years old or younger, the NEJ 002 trial reported

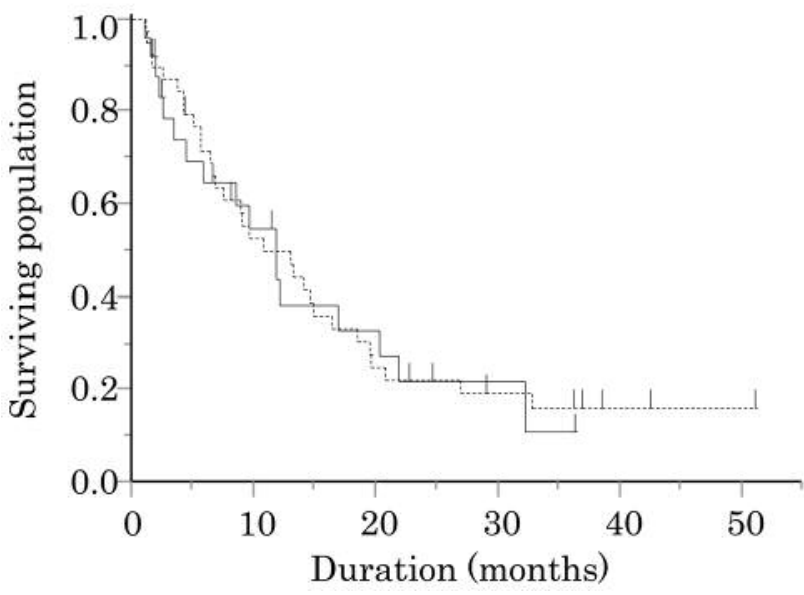

Figure 1. Kaplan-Meier curve for progression-free survival (PFS) in the younger and elderly patient groups. The median progression-free survival time was 11.8 months in the elderly patient group (solid line) and 10.8 months in the younger patient group (dashed line).

encountering appetite loss in $14.9 \%$ of patients, while the WJOG 3405 trial reported no cases of appetite loss $(4,5)$. These clinical studies appear to suggest that appetite loss is not a major adverse effect of EGFR-TKIs. The frequency of appetite loss in our study was slightly higher, however, we believe that our results are in line with previously reported data. A phase II study of patients with lung cancer harboring EGFR gene mutation, including younger and elderly patients, reported that $35 \%$ of the patients complained of appetite loss (11), and other clinical studies have reported a high frequency of appetite loss in elderly patients aged 75 years or older receiving EFGR-TKIs (10-13), which the finding in our study is consistent with.

Diarrhea and oral mucositis were also encountered more frequently in elderly patients, although the differences in the frequencies between the two groups were not statistically significant. We cannot explain the mechanism underlying the development of appetite loss in patients receiving EGFRTKIs because no comprehensive clinical tests, including fiberoptic gastrointestinal endoscopy, were performed in all the patients who complained of appetite loss. However, given the frequent occurrence of diarrhea and oral mucositis in elderly patients, appetite loss may be associated with gastrointestinal disorders caused by EGFR-TKIs.

The present study had several limitations. Firstly, the study included only patients from a single institution, and the sample size was relatively small; therefore, the data might not be representative of the general population. Secondly, because evaluation of adverse events was not based on preplanned criteria, description of appetite loss on the medical charts may have been influenced by the subjectivity of the physician in charge. 
In conclusion, our findings showed that appetite loss occurs more frequently in elderly patients receiving treatment with EGFR-TKIs compared to younger patients; nevertheless, clinical benefits of this treatment were also obtained in elderly patients. Our findings suggest that appropriate dose reduction may be necessary in elderly patients treated with EGFR-TKIs.

\section{Conflicts of Interest}

None.

\section{References}

1 The Non-Small Cell Lung Cancer Collaborative Group Chemotherapy in non-small cell lung cancer: a meta-analysis using updated data on individual patients from 52 randomized clinical trials. BMJ 311: 899-909, 1995.

2 Paz-Ares LG, de Marinis F, Dediu M, Thomas M, Pujol JL, Bidoli P, Molinier O, Sahoo TP, Laack E, Reck M, Corral J, Melemed S, John W, Chouaki N, Zimmermann AH, VisserenGrul C and Gridelli C: PARAMOUNT: Final overall survival results of the phase III study of maintenance pemetrexed versus placebo immediately after induction treatment with pemetrexed plus cisplatin for advanced nonsquamous non-small-cell lung cancer. J Clin Oncol 31: 2895-2902, 2013.

3 Sandler A, Gray R, Perry MC, Brahmer J, Schiller JH, Dowlati A, Lilenbaum R and Johnson DH: Paclitaxel-carboplatin alone or with bevacizumab for non-small-cell lung cancer. Engl J Med 355: 2542-2550, 2006.

4 Maemondo M, Inoue A, Kobayashi K, Sugawara S, Oizumi S, Isobe H, Gemma A, Harada M, Yoshizawa H, Kinoshita I, Fujita Y, Okinaga S, Hirano H, Yoshimori K, Harada T, Ogura T, Ando M, Miyazawa H, Tanaka T, Saijo Y, Hagiwara K, Morita S and Nukiwa T; North-East Japan Study Group: Gefitinib or chemotherapy for non-small-cell lung cancer with mutated EGFR. N Engl J Med 362: 2380-2388, 2010.

5 Mitsudomi T, Morita S, Yatabe Y, Negoro S, Okamoto I, Tsurutani J, Seto T, Satouchi M, Tada H, Hirashima T, Asami K, Katakami N, Takada M, Yoshioka H, Shibata K, Kudoh S, Shimizu E, Saito H, Toyooka S, Nakagawa K and Fukuoka M; West Japan Oncology Group: Gefitinib versus cisplatin plus docetaxel in patients with non-small-cell lung cancer harbouring mutations of the epidermal growth factor receptor (WJTOG3405): an open label, randomised phase 3 trial. Lancet Oncol 11: 121-128, 2010.

6 Zhou C, Wu YL, Chen G, Feng J, Liu XQ, Wang C, Zhang S, Wang J, Zhou S, Ren S, Lu S, Zhang L, Hu C, Hu C, Luo Y, Chen L, Ye M, Huang J, Zhi X, Zhang Y, Xiu Q, Ma J, Zhang L and You C: Erlotinib versus chemotherapy as first-line treatment for patients with advanced EGFR mutation-positive non-smallcell lung cancer (OPTIMAL. CTONG-0802: a multicentre, open-label, randomised phase 3 study. Lancet Oncol 12: 735742, 2011.

7 Rosell R, Carcereny E, Gervais R, Vergnenegre A, Massuti B, Felip E, Palmero R, Garcia-Gomez R, Pallares C, Sanchez JM, Porta R, Cobo M, Garrido P, Longo F, Moran T, Insa A, De Marinis F, Corre R, Bover I, Illiano A, Dansin E, de Castro J, Milella M, Reguart N,
Altavilla G, Jimenez U, Provencio M, Moreno MA, Terrasa J, Muñoz-Langa J, Valdivia J, Isla D, Domine M, Molinier O, Mazieres J, Baize N, Garcia-Campelo R, Robinet G, Rodriguez-Abreu D, Lopez-Vivanco G, Gebbia V, Ferrera-Delgado L, Bombaron P, Bernabe R, Bearz A, Artal A, Cortesi E, Rolfo C, Sanchez-Ronco M, Drozdowskyj A, Queralt C, de Aguirre I, Ramirez JL, Sanchez JJ, Molina MA, Taron M and Paz-Ares L; Spanish Lung Cancer Group in collaboration with Groupe Français de PneumoCancérologie and Associazione Italiana Oncologia Toracica: Erlotinib versus standard chemotherapy as first-line treatment for European patients with advanced EGFR mutation-positive nonsmall-cell lung cancer (EURTAC): a multicentre, open-label, randomised phase 3 trial. Lancet Oncol 13: 239-246, 2012.

8 Tateishi K, Ichiyama T, Hirai K, Agatsuma T, Koyama S, Hachiya T, Morozumi N, Shiina T and Koizumi T: Clinical outcomes in elderly patients administered gefitinib as first-line treatment in epidermal growth factor receptor-mutated nonsmall-cell lung cancer: retrospective analysis in a Nagano Lung Cancer Research Group study. Med Oncol 30: 450, 2013.

9 Yoshioka H, Komuta K, Imamura F, Kudoh S, Seki A and Fukuoka M: Efficacy and safety of erlotinib in elderly patients in the phase IV POLARSTAR surveillance study of Japanese patients with non-small-cell lung cancer. Lung Cancer 86: 201206, 2014.

10 Maemondo M, Minegishi Y, Inoue A, Kobayashi K, Harada M, Okinaga S, Morikawa N, Oizumi S, Tanaka T, Isobe H, Kudoh $\mathrm{S}$, Hagiwara K, Nukiwa T and Gemma A: First-line gefitinib in patients aged 75 or older with advanced non-small cell lung cancer harboring epidermal growth factor receptor mutations: NEJ 003 study. J Thorac Oncol 7: 1417-1422, 2012.

11 Goto K, Nishio M, Yamamoto N, Chikamori K, Hida T, Maemondo M, Katakami N, Kozuki T, Yoshioka H, Seto T, Fukuyama T and Tamura T: A prospective, phase II, open-label study (JO22903) of first-line erlotinib in Japanese patients with epidermal growth factor receptor $(E G F R)$ mutation-positive advanced non-small-cell lung cancer (NSCLC). Lung Cancer 82: 109-114, 2013.

12 Takahashi K, Saito H, Hasegawa Y, Ando M, Yamamoto M, Kojima E, Sugino Y, Kimura T, Nomura F, Ogasawara T, Shindoh J, Yoshida N and Suzuki R: First-line gefitinib therapy for elderly patients with non-small cell lung cancer harboring EGFR mutation: Central Japan Lung Study Group 0901. Cancer Chemother Pharmacol 74: 721-727, 2014.

13 Inoue Y, Inui N, Asada K, Karayama M, Matsuda H, Yokomura K, Koshimizu N, Imokawa S, Yamada T, Shirai T, Kasamatsu N and Suda T: Phase II study of erlotinib in elderly patients with non-small cell lung cancer harboring epidermal growth factor receptor mutations. Cancer Chemother Pharmacol 76: 155-161, 2015.

14 Eisenhauer EA, Therasse P, Bogaerts J, Schwartz LH, Sargent D, Ford R, Dancey J, Arbuck S, Gwyther S, Mooney M, Rubinstein L, Shankar L, Dodd L, Kaplan R, Lacombe D and Verweij J: New response evaluation criteria in solid tumours: revised RECIST guideline (version 1.1). Eur J Cancer 45: 228-247, 2009.

Received July 10, 2016

Revised July 31, 2016

Accepted August 1, 2016 